Original Research Paper

\title{
Pembimbingan Pembuatan Pupuk Organik Rumput Laut Sederhana dan Pentingnya Kualitas Sanitasi Lingkungan dalam Rangka Pencegahan Stunting
}

\author{
Eka Sunarwidhi Prasedya ${ }^{1,2}$, Dewi Puspitorini Husodo ${ }^{3,4}$, Angga Susmana Abidin ${ }^{1}$, Nanda Sofian Hadi \\ Kurniawan $^{1}$, Bq Tri Khairina Ilhami ${ }^{1}$, Indah Alibiah Putri Kirana ${ }^{1}$, Aluh Nikmatullah ${ }^{5}$, Sri Widyastuti ${ }^{6}$, \\ Ahmad Jupri ${ }^{*}$

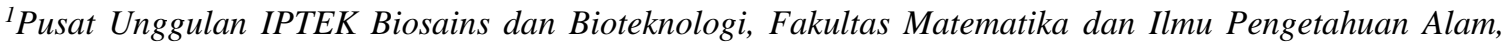 \\ Universitas Mataram, Mataram, Indonesia \\ ${ }^{2}$ Program Studi Biologi, Fakultas Matematika dan Ilmu Pengetahuan Alam, Universitas Mataram, Mataram, \\ Indonesia \\ ${ }^{3}$ CV. Organik Medika Biotek, Lombok Barat, Indonesia \\ ${ }^{4}$ Rumah Sakit Umum Daerah Patut Patuh Patju, Gerung, Lombok Barat, Nusa Tenggara Barat, Indonesia \\ ${ }^{5}$ Program Studi Agroekoteknologi, Fakultas Pertanian, Universitas Mataram, Mataram, Indonesia \\ ${ }^{6}$ Program Studi Ilmu dan Teknologi Pangan, Fakultas Teknologi Pangan, Universitas Mataram, Mataram, \\ Indonesia \\ ${ }^{7}$ Program Studi Ilmu Lingkungan, Fakultas Matematika dan Ilmu Pengetahuan Alam, Universitas \\ Mataram, Mataram, Indonesia
}

https://doi.org/10.29303/jpmpi.v3i2.1245

Sitasi: Prasedya, E. S., Husodo, D. P., Abidin, A. S., Kurniawan, N. S. H., Ilhami, B. T. K., Kirana, I. A. P., Nikmatullah, A., Widyastuti, S \& Jupri, A. (2022). Pembimbingan Pembuatan Pupuk Organik Rumput Laut Sederhana dan Pentingnya Kualitas Sanitasi Lingkungan dalam Rangka Pencegahan Stunting. Jurnal Pengabdian Magister Pendidikan IPA, 5(1)

\section{Article history}

Received: 10 November 2021

Revised: 01 Februari 2022

Accepted: 05 Februari 2022

*Corresponding Author:

Ahmad Jupri, Program Studi

Ilmu Lingkungan, Fakultas

Matematika dan Ilmu

Pengetahuan Alam,

Universitas Mataram,

Mataram, Indonesia;

Email:

ahmadjupri@unram.ac.id
Abstract: Rumput laut coklat Nusa Tenggara Barat, seperti Sargassum dan Turbinaria yang melimpah keberadaannya diketahui mengandung hormon pertumbuhan tanaman dengan kadar yang cukup tinggi. Penggunaan pupuk kimia yang berlebihan pada budidaya tanaman menyebabkan meningkatnya biaya produksi, menurunkan kesuburan tanah, dan mencemari lingkungan yang berpotensi menimbulkan dampak negatif bagi kesehatan dan keamanan pangan. Oleh karena itu, substitusi pupuk kimia dan perangsang tumbuh sintetis dengan bahan alam. merupakan solusi terbaik untuk mengatasi masalah tersebut. Substitusi pupuk organik akan menurunkan kontaminasi bahan kimia berbahaya pada air tanah sehingga kualitas sanitas air dan lingkungan dapat dibenahi. Menjaga kebersihan sanitasi dan memenuhi kebutuhan air bersih merupakah salah satu tindakan pencegahan stunting yang digalakkan oleh Kementerian Kesehatan. Desa Puyung menjadi target dalam program ini mengingat prevalensi kejadian gizi kurang dan stunting di wilayah tersebut terbilang cukup tinggi dan memerlukan perhatian. Terlebih Desa Puyung merupakan salah satu desa binaan Universitas Mataram. Program ini dikemas dalam bentuk penyuluhan dan demonstrasi serta pembimbingan langkah-langkah aplikasi pupuk organik berbahan dasar rumput laut NTB. Materi edukatif disampaikan oleh tiga orang narasumber yaitu Eka Sunarwidhi Prasedya, M.Sc., Ph.D., dan Dr. H. Ahmad Jupri, M.Eng selaku perwakilan Pusat Unggulan IPTEK Biosains dan Bioteknologi Universitas Mataram, serta dr. Dewi Puspitorini Husodo, Sp.An. selaku pimpinan CV. Organik Medika Biotek yang menjadi mitra dalam kegiatan kali ini. Materi penyuluhan edukatif yang disampaikan meliputi substansi berikut : (1) Eksplorasi rumput laut sebagai bahan dasar pupuk organik; (2) Peran pengaplikasian PORL dalam langkah preventif pencegahan stunting; (3) Tahapan pembuatan PORL sederhana.

Keywords: Stunting,Rumput Laut, Pupuk Organik, Sanitasi, Puyung 


\section{Pendahuluan}

Nusa Tenggara Barat (NTB) merupakan salah satu sentra pengembangan rumput laut. Data DKP tahun 2016 menyebutkan produksi rumput laut tahun 2015 meningkat sekitar 19,6\%. Peningkatan produksi tersebut dikarenakan sebaran sentra produksi pada tiap kabupaten. Pesatnya produksi rumput laut ini mendorong kebijakan pemerintah daerah Nusa Tenggara Barat dalam upaya mengentaskan kemiskinan dengan penetapan kawasan minapolitan rumput laut yang dituangkan dalam bentuk program PIJAR (Peningkatan daya saing Sapi, Jagung dan Rumput Laut).

Berdasarkan uraian sebelumnya maka rumput laut memiliki nilai ekonomi yang tinggi selain karena permintaan pasar yang meningkat juga karena komoditi ini mengandung senyawa hidrokoloid seperti karaginan, agar, dan alginat yang merupakan bahan baku industri pangan dan farmasi. Rumput laut memiliki pasar yang luas mulai dari tingkat lokal, regional, nasional, bahkan internasional.Rumput laut dapat dipasarkan pada setiap fase pertumbuhannya, yaitu pada umur $1,2,3,4,5$, atau 6 minggu komoditi ini dapat diperdagangkan.

Namun komoditas rumput laut yang marak dimanfaatkan masyarakat dan telah memiliki pasar adalah rumput laut jenis Kappaphycus alvarezii dan Eucheuma cottonii. Sedangkan pada beberapa wilayah pesisir perairan Nusa Tenggara Barat (NTB) ditemukan berbagai jenis dan spesies rumput laut yang belum termanfaatkan secara optimal. Rumput laut coklat jenis Sargassum merupakan salah satu jenis rumput laut dengan jumlah yang melimpah namun tidak tereksplorasi dengan optimal. Rumput laut Sargassum sp.lebih umum dikenal sebagai debris pantai atau pengotor wilayah pesisir pantai. Dibalik fakta ini, rumput laut Sargassum memiliki banyak manfaat.

Rumput laut coklat Nusa Tenggara Barat, seperti Sargassum dan Turbinaria yang melimpah keberadaannya diketahui mengandung hormon pertumbuhan tanaman (pada fraksi cair) dan mineral essensial (pada fraksi padat) dengan kadar yang cukup untuk mendukung pertumbuhan dan produksi tanaman pangan dan hortikultura (Sunarpi dkk., 2010; Sunarpi dkk., 2014; Nikmatullah dkk., 2014; Sunarpi dkk., 2019). Hingga saat ini, telah dihasilkan prototype pupuk cair (biostimulan) dan pupuk padat (biofertilizer) alga coklat yang merangsang dan memacu pertumbuhan dan produksi tanaman padi dan tanaman sayuran, sebagai luaran skim penelitian terapan KEMENRISTEK DIKTI sejak tahun 2018-2019. Atas berlandaskan prototype yang telah dikembangkan, program pengabdian kepada masyarakat (PKM) ini dirancang agar dapat mengedukasi masyarakat desa binaan untuk membuat pupuk organik berbahan dasar rumput laut skala rumah tangga.

Penggunaan pupuk kimia dan perangsang pertumbuhan sintetis yang berlebihan dalam budidaya tanaman menyebabkan meningkatnya biaya produksi dan menurunkan pendapatan petani, menurunkan kesuburan tanah, dan mencemari lingkungan yang berpotensi menimbulkan dampak negatif bagi kesehatan dan keamanan pangan. Oleh karena itu, substitusi pupuk kimia dan perangsang tumbuh sintetis dengan bahan alam yang ketersediaannya melimpah dan ramah lingkungan merupakan solusi terbaik untuk mengatasi masalah tersebut. Selain dapat mengatasi permasalahan ekonomi dan lingkungan, substitusi pupuk organik dalam bidang pertanian juga dapat mengatasi masalah kesehatan.

Substitusi pupuk organik akan menurunkan kontaminasi bahan kimia berbahaya pada air tanah sehingga kualitas sanitas air dan lingkungan dapat dibenahi. Air bersih merupakan komonen penting dalam sanitasi dan salah satu unsur penting dalam penerapan perilaku hidup bersih dan sehat, di Semua Desa Lokus stunting Pada Tahun 2018 (kesmas.kemkes.go.id). Menjaga kebersihan sanitasi dan memenuhi kebutuhan air bersih merupakah salah satu tindakan pencegahan stunting yang digalakkan oleh Kementerian Kesehatan. Oleh karena itu, secara garis besar penggunaan pupuk organik rumput laut akan memperbaiki kualitas air tanah disekitar tempat tinggal warga. Kadar logam besar, bahan kimia berbahaya, dan residu kimia lainnya yang memicu kejadian stunting pada anak dan balita diperkirakan dapat ditekan dengan penggunaan pupuk organik. 
Program PKM ini bertujuan untuk mengedukasi dan melakukan pembinaan pembuatan pupuk organik rumput laut kepada warga desa binaan di Desa Puyung Kecamatan Jonggat, Kabupaten Lombok Tengah. Masyarakat setempat yang mayoritas berprofesi sebagai petani menjadi sasaran dalam program ini. Melalui program ini diharapkan masyarakat setempat dapat perlahan melakukan subsituti pupuk anorganik menjadi pupuk organik dan dengan harapan dapat memperbaiki kualitas air dan sanitasi lingkungan dalam rangka pencegahan stunting.

\section{Metode}

Kegiatan pengabdian kepada masyarakat (PKM) ini dilakukan dengan kegiatan sosialisasi dan edukasi melalui pendampingan, penyuluhan, dan pelatihan dengan berbagai program kegiatan utama dan pendukung. Program kegiatan utama, yaitu memberikan wawasan atau edukasi terhadap masyarakat di Desa Puyung dengan :

1. Penyuluhan dan sosialisasi kepada masyarakat tentang pemanfaatan rumput laut sebagai bahan baku pupuk organik.

2. Mengedukasi masyarakat mengenai dampak penggunaan pupuk anorganik berlebih

3. Penyuluhan dan sosialisasi kepada masyarakat tentang hubungan antara perbaikan sanitasi dan pencegahan stunting

\section{Hasil dan Pembahasan}

Rumput laut tidak hanya dimanfaatkan sebagai bahan pangan namun juga dapat digunakan sebagai bahan dasar pupuk organik. Rumput laut mengandung mineral esensial seperti $\mathrm{Fe}, \mathrm{Ca}, \mathrm{Cu}$, $\mathrm{Cl}, \mathrm{K}, \mathrm{Mg}$, dan $\mathrm{Mn}$ serta mengandung zat pengatur tumbuh atau hormone pertumbuhan diantaranya auksin, sitokin dan giberilin yang berguna untuk memicu pertumbuhan dan meingkatkan produksi hasil panen petani (Basmal, 2009). Rumput laut yang menjadi salah satu komoditas ekspor utama Nusa Tenggara Barat adalah rumput laut jenis Kappaphycus alvarezii dan Eucheuma cottonii. Kedua jenis rumput laut ini banyak dibudidayakan oleh masyarakat pesisir pantai. Namun seiring meningkatnya pembangunan sektor pariwisata, keseimbangan ekosistem pesisir pantai lokasi budidaya rumput laut jenis ini terganggu sehingga produksinya kian hari terus menurun.

Dalam kurun waktu 10 tahun terakhir, peneliti terus mengembangkan rumput laut jenis Sargassum sebagai bahan baku pupuk organik yang potensial. Rumput laut jenis Sargassum saat ini dapat ditemukan secara melimpah di pesisir perairan Lombok Barat, Lombok Timur, dan Lombok Tengah. Sargassum spp. mampu tumbuh liar dan mencapai puncak masa panennya saat musim penghujan. Potensi kemelimpahan ini dikemas menjadi teknologi tepat guna oleh penelitia dalam bentuk pupuk organik rumput laut. Pupuk organik rumput laut (PORL) berbahan dasar Sargassum sp.terbukti aman terhadap lingkungan dan sanitasi air karena mengandung kadar logam berat dalam jumlah yang telah dipersyaratkan (Widyastuti dkk., 2021). Aspek penting lain yang menjadi keunggulan PORL adalah mampu meningkatkan hasil produksi tanaman pangan utamanya padi, jagung, dan tomat (Sunarpi dkk., 2021; Sunarwidhi dkk., 2019; Prasedya dkk., 2019; Widyastuti dkk., 2019; Jupri dkk., 2019).

Selain meningkatkan massa produksi pasca panen, PORL juga dilaporkan mampu menjadi media perpindahan mineral esensial. Tanaman pangan yang dihasilkan akan memiliki profil gizi yang lebih baik jika dibandingkan dengan tanaman pangan yang diolah menggunakan pupuk sintetik atau anorganik. Hal ini yang melandasi terwujudnya program pengabdian kepada masyarakat di Desa Puyung, Kecamatan Jonggat, Kabupaten Lombok Tengah. Desa Puyung merupakan salah satu desa binaan Universitas Mataram yang secara berkala didampingi dan dibina untuk mencapai berbagai target pengembangan desa binaan. Selain itu, pemilihan Desa Puyung sebagai target pengabdian adalah tingginya prevalensi stunting di desa tersebut. Hal tersebut telah dilansir dari fasilitas kesehatan setempat. Luaran sederhana yang diharapkan dari program pengabdian ini adalah terwujudnya masyarakat yang mandiri dalam sektor pertanian dan perekonomian dengan mengedepankan penggunaan pupuk organik dibandingkan pupuk anorganik. Selain aspek pertanian dan ekonomi, aplikasi PORL juga turut berkontribusi sebagai alternatif solusi permasalahan kesehatan khsusunya stunting karena perbaikan gizi tanaman pangan dan 
sanitasi lingkungan yang aman akan meminimalkan prevalensi kejadian balita stunting.

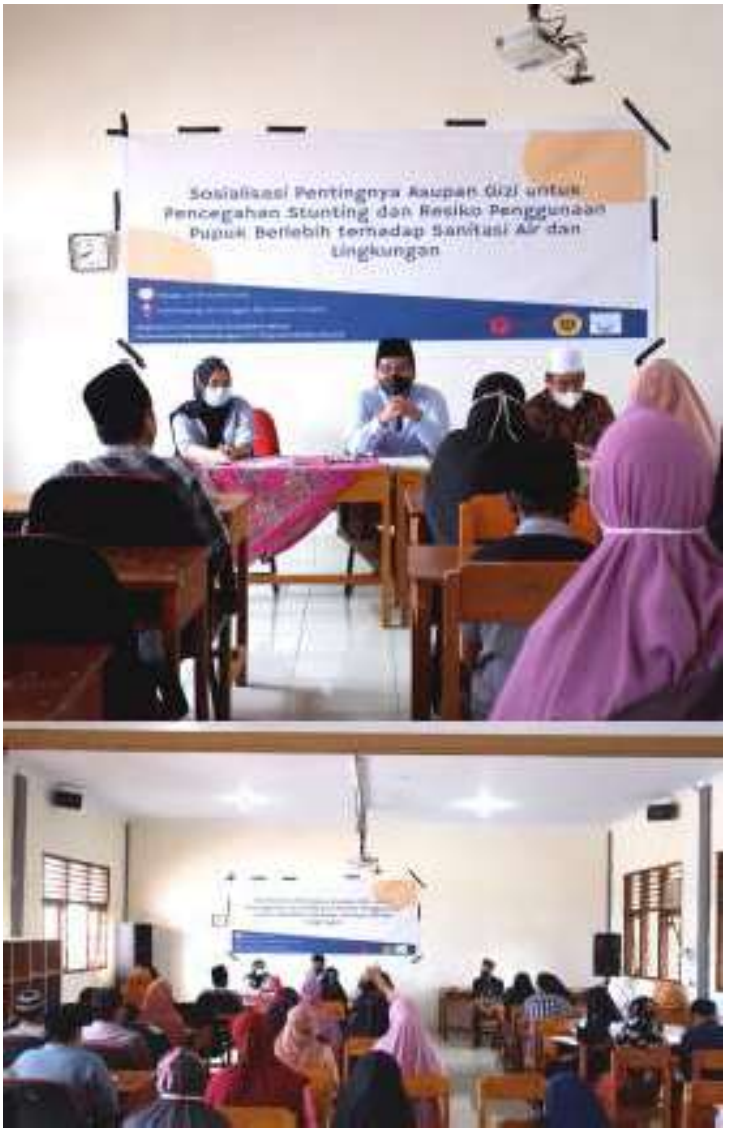

Gambar 1. Sesi sosialisasi dan penyuluhan

Langkah-langkah atau tahapan yang akan dilaksanakan untuk mencapai hasil yang diharapkan diantaranya adalah tahap penyuluhan (pembelajaran) yang dilanjutkan dengan tahapan demonstrasi pembuatan pupuk organik berbahan dasar rumput laut. Dalam tahap penyuluhan yang disampaikan oleh Eka Sunarwidhi Prasedya, M.Sc., PhD. selaku Ketua Pusat Unggulan IPTEK Biosains dan Bioteknologi Universitas Mataram (Gambar 1) masyarakat diperkenalkan dengan jenis rumput laut melimpah di perairan Lombok dan usaha pemanfaatannya. Ditambah lagi, Eka Sunarwidhi Prasedya, M.Sc., PhD. juga tidak lupa menyampaikan keunggulan penggunaan PORL kepada masyarakat. Dalam sesi penyuluhan ini juga turut hadir dr. Dewi Puspitorini Husodo, Sp.An selaku mitra dalam program ini yaitu CV. Organik Medika Biotek menyampaikan materi edukatif terkait kiat dan langkah pencegahan stunting serta Dr. H. Ahmad
Jupri, M.Eng. selaku dosen Program Studi Ilmu Lingkungan Fakultas MIPA Universitas Mataram yang menyampaikan materi interaktif mengenai dampak buruk penggunaan pupuk anorganik berlebih pada lingkungan dan bermuara pada peningkatan prevalensi gizi kurang dan bahkan stunting (Gambar 2).

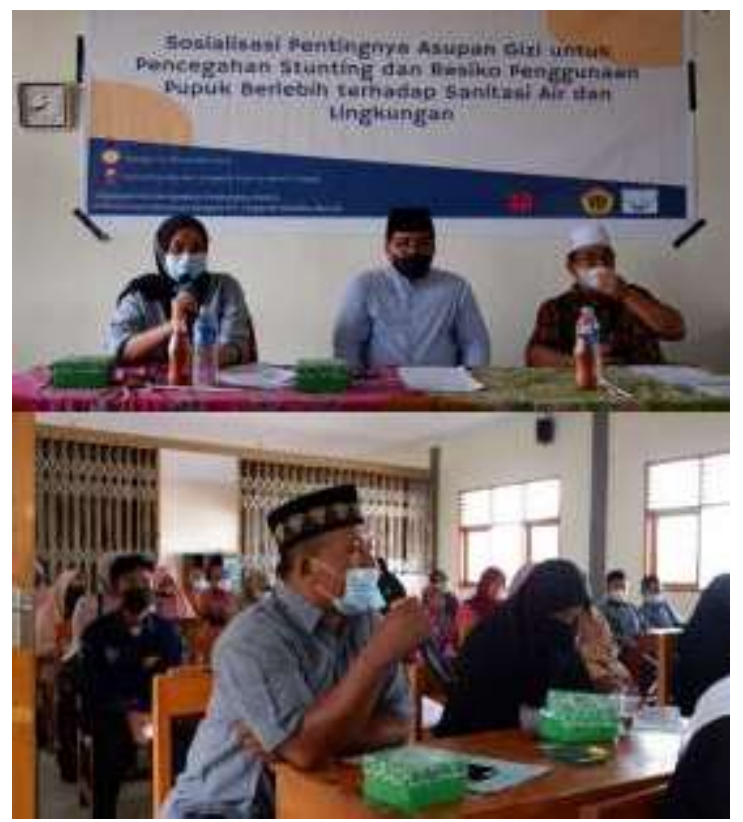

Gambar 2. Sesi penyampaian materi sektor kesehatan dan sesi diskusi

Dalam sesi demonstrasi, peserta yang berjumlah 48 orang diajak untuk bersama sama menyaksikan proses pembuatan PORL dan tahapan preparasi rumput laut hingga dapat digunakan sebagai bahan dasar pupuk. Rumput laut yang digunakan adalah jenis rumput laut Sargassum sp.yang melimpah diperairan Lombok Tengah khususnya pantai Kuta dan Tanjung Aan serta di Lombok Barat khususnya pantai Batu Layar dan sekitarnya. Rumput laut harap diambil hingga substratnya saat air laut sedang surut. Rumput laut selanjutnya melalui proses pengeringan dan perubahan bentuk menjadi lebih kecil. Kemudian rumput laut dengan komponen penyusun lain seperti massa serbuk gergaji, EM4, dan molase digabungkan menjadi satu massa utama dan diinkubasi selama $3-4$ minggu. PORL dengan kualitas baik ditandai oleh bentuk yang halus seperti tanah, berwarna kehitaman dan tidak berbau busuk. 
Peserta merupakan warga lokal yang berdomisili di Desa Puyung dengan berbagai macam profesi. Namun mayoritas dari mereka berprofesi sebagai petani, ibu rumah tangga, dan buruh ataupun pengusahan rumah olahan tahu. Peserta terlihat antusias dan juga mengajukan beberapa pertanyaan serta kendala yang mungkin dihadapi selama proses pembuatan PORL secara mandiri. Sesi diskusi dan tanya jawab antara pemateri dan peserta berjalan selama 60 menit.

Evaluasi dilakukan pada akhir kegiatan, yaitu dengan menilai pemahaman, keterampilan dan perubahan sikap petani dalam menerima inovasi teknologi pembuatan kompos/pupuk organik dengan bahan baku limbah rumput laut. Masyarakat juga ditanyakan mengenai ketertarikannya untuk mengembangan produk pupuk organik ini sebagai produk desa. Peserta memberikan timbal balik yang positif dengan menyampaikan bahwa jika kedepannya terus dilakukan pendampingan oleh pihak Universitas Mataram maka produk ini dapat diolah dan diproduksi dalam skala yang lebih besar dan tentunya dengan bekerja sama bersama koperasi desa atau badan usaha milik desa (BUMDES).

Kegiatan diakhiri dengan sesi foto bersama serta penyerahan secara simbolis produk unggulan Pusat Unggulan IPTEK Biosains dan Bioteknologi Universitas Mataram (Gambar 3). Dalam sesi foto tersebut disampaikan harapan dan saran agar kegiatan ini dapat secara rutin dilaksanakan di Desa Puyung sebagai salah satu desa binaan Universitas Mataram.

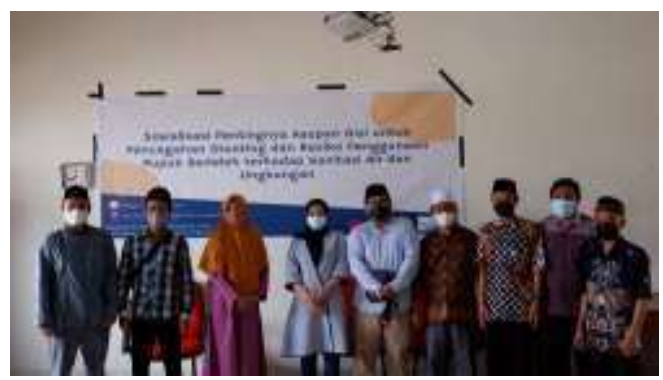

Gambar 3. Sesi dokumentasi foto bersama peserta dan mitra program pengabdian

\section{Kesimpulan}

Substansi penyuluhan dan sosialisasi yang disampaikan dalam program pengabdian di Desa Puyung meliputi :

1. Eksplorasi penggunaan rumput laut jenis Sargassum sp. dapat menjadi alternative solusi untuk membangun kemandirian masyarakat setempat pada sektor pertanian dan perekonomian

2. Aplikasi pupuk organik rumput laut (PORL) secara tidak langsung akan memperbaiki kualitas sanitasi air sumur dan lingkungan. Secara berantai, dampak positif ini juga dapat menurunkan prevalensi stunting di Desa Puyung

3. Tahapan pembuatan PORL sederhana adalah pengambilan dan preparasi sampel, pencampuran, dan inkubasi.

\section{Saran}

Waktu yang lebih panjang dan intensitas yang lebih berjangka sangat diperlukan dalam program berikutnya untuk dicapai hasil optimal yang diharapkan. Serta cakupan mitra desa yang dilibatkan juga dapat diperluas kembali.

\section{Ucapan Terima Kasih}

Terimakasih disampaikan kepada Badan Riset dan Inovasi Nasional (BRIN) melalui skim Prioritas Riset Nasional Stunting dengan nomor kontrak 4314/UN18.L1/PP/2021 dan nomor SP DIPA-023.17.1.69.439/2021 Tahun Anggaran 2021yang telah memberikan hibah dana dalam program pengabdian ini.

\section{Daftar Pustaka}

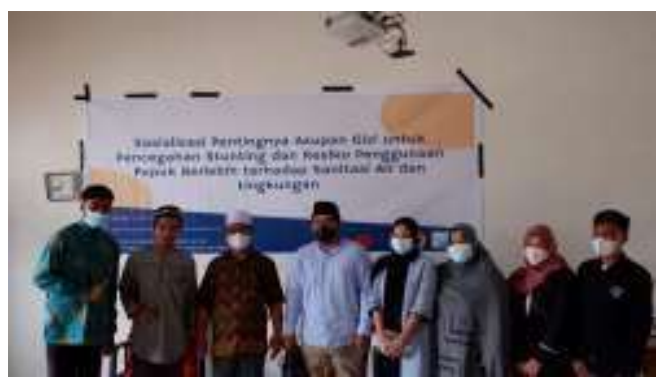


Basmal, J. 2009. Prospek Pemanfaatan Rumput Laut Sebagai Bahan Pupuk Organik. Squalen, Vol. 4 No. 1, hal. $1-8$.

Jupri, A. et al. 2019. Growth and Yield of Rice Plants Sprayed with Sargassum polycystum Extracted with Different Concentrations. AIP Conference Proceedings. 2199, 070009 (2019) https://doi.org/10.1063/1.5141323

Nikmatullah, A., Gazali, M., Kurnianingsih, R., Mulyawarni, Sunarpi, 2014. Growth Promoting Capability Of Aquadest-Extracts From Different Macro Algae Obtained In Lombok Island, Indonesia To Growth Of Rice-Paddy Plant Agroteksos Vol. 24 No. 3. Hal : $178-185$.

Prasedya, E.S., et al. 2019. Effect of Liquid and Solid Brown Algae Extract on Growth and Yield of Rice Plants. AIP Conference Proceedings. 2199, 070007 (2019). https://doi.org/10.1063/1.5141321

Sunarpi et al. 2019. Growth and Yield of Rice Plants Supplied with Solid Brown Algae in Combination With Inorganic Fertilizers. AIP Conference Proceedings. 2199.

Sunarpi et al. 2019. The Evidence Suggesting that Turbinaria murayana Extract Induce Remobilization of Macromolecule from Leafs to Grain of Rice Plants. AIP Conference Proceedings. 2199.

Sunarpi, Ghazali, M., Kurniangsih, R.,Nikmatullah, A., Eem,. L.P. 2014. Diversity and Distribution of Natural Population of Eucheuma J. Agardh and Kappaphycus Doty in Nusa Tenggara Barat Indonesia. Malaysian Journal of Science. 32 (SCS Sp Issue). hal. 151-164.

Sunarpi, H., Nimatullah, A., Sunarwidhi, A. L., Jihadi, A., Ilhami, B. T. K., Ambana, Y., Rinaldi, R., Jupri, A., Widyastuti, S., Prasedya, E.S. 2021. Combination of inorganic and organic fertilizer in rice plants (Oryza sativa) in screen houses. IOP Conf. Series: Earth and Environmental Science, 712(2021) : 012035. doi:10.1088/1755-1315/712/1/012035

Sunarpi, Jupri, A., Kurnianingsih, R., Julisaniah, N. I., Nikmatullah, A. 2010. Effect of seaweed extracts on growth and yield of rice paddy plants. Nusantara Biocsience. Vol 2. No. 2, hal 73-77
Sunarwidhi, Anggit Listya, et al. 2019. Growth and Yield of Rice Plants Grown in Media Containing Several Formulation of Brown Algae Organic Fertilizer Containing Brown Algae. AIP Conference Proceedings. 2199, 070005 https://doi.org/10.1063/1.5141319

(2019).

Widyastuti, S., Geraldine, B. A. F.D., Sunarwidhi, A.L., Aryana, M.D., Sunarpi, H. 2019. The Use of Brown Algae Extract to Extend Shelf Life and Improve Tomato Fruits Post Harvest Quality. AIP Conference Proceedings. 2199, 070008 (2019). https://doi.org/10.1063/1.5141322

WIdyastuti, S., Jupri, A., Nikmatullah, A., Kurniawan, N. S. H., Kirana, I. A. P., Hernawan, A., Sunarpi, H., Prasedya, E. S. 2021. Analyses of organic matter and heavy metal composition in formulated macroalgae-based organic fertilizer. IOP Conf. Series: Earth and Environmental Science, $\quad 913(2021)$ : 012024. doi:10.1088/1755-1315/913/1/012024 